\title{
Sterilizing procedures for heart-lung machines
}

\author{
J. C. KELSEY \\ From the Central Public Health Laboratory, Colindale, London
}

In the early days of cardiac surgery, the apparatus used for extracorporeal circulation was of necessity hand-made out of whatever materials were then available. At the time, these were largely heatsensitive plastics and therefore from the beginning the problem of sterilizing such equipment had to be faced. It is not easy to collect information about trouble caused by unsterile heart-lung machines, and indeed it is unlikely that all or even most of such incidents would be reported.

In 1957 Keown, Gilman, and Bailey reported five deaths from Pseudomonas infection following the use of a heart-lung machine that had been sterilized by quaternary ammonium compounds. Formalin has been used but this is very unpleasant and great care must be taken to get rid of excess formalin before the apparatus is used. It is therefore not surprising that gaseous sterilizing agents were seriously considered quite early on. Ethylene oxide was examined for this type of application by Phillips and others of the United States Army Chemical Corps at Camp Detrick during the Second World War, and most of our information comes from them and their work, for it was to them that the earlier workers turned for advice.

Ethylene oxide has many advantages to offer as a disinfecting or sterilizing agent. It is a gas with good penetrating powers and with a few exceptions it does not damage materials. It is active against a wide range of microorganisms including spores. Although it is more effective as temperature rises, it is satisfactorily biocidal at comparatively low temperatures. The lethal effect depends on the concentration, on the temperature, on the humidity; and on the time; in theory a sterilizing procedure could be defined in these terms. More recent work has shown that the surface on which organisms are presented to the gas may be important, organisms dried onto impervious materials such as glass, plastic, or metal being much harder to kill than organisms dried onto paper or fabric. At the sort of concentrations normally used, an exposure of four hours would be required at $55^{\circ} \mathrm{C}$. and of 18 hours at $20^{\circ} \mathrm{C}$. The situation, however, is not quite as simple as this would suggest and there are a number of very definite drawbacks to the use of ethylene oxide as a sterilizing agent. In the first place it is explosive whe mixed with air or oxygen and this can constitute real hazard which can be largely removed by two techniques. In Germany, gas is used in sealed chambers run at subatmospheric pressures, so that any leak that occurs is always inwards rather thag outwards. In the United States gas is nearly always used in the form of a mixture containing not more than $20 \%$ of ethylene oxide, together with another inert gas such as carbon dioxide or one of the freons. It has been shown that these mixtures are nof explosive in any circumstances, even when mixes with air or oxygen. Another drawback is that the gas is toxic to man and animals. Its toxicity is said to approximate to that of ammonia, and warning is given by a pungent smell. The hazard to those wh' use the gas as a disinfecting agent is probably not great, and can be surmounted by adequate training and normal factory safety precautions. It is unfo tunately true that plastics and rubber goods wigl absorb the gas and give it off again when they are removed from the sterilizer, and, for example, gas sterilized rubber boots have caused severe burns whe? worn too soon after sterilization. It is for this reason that when ethylene oxide is used for sterilizing plast equipment of all sorts adequate time must be allowed for airing and for the toxic gas to be dissipated.

The many variables that control the effectivenes of ethylene oxide as a sterilizing agent are in practice very difficult to control. Therefore it is not realls possible to lay down a safe standard sterilizing cycle that will apply to all types of load in all circum stances. For example, a load composed of papep or fabric may take up heat very slowly and therefore. be difficult to sterilize. Similarly, such a load masp absorb ethylene oxide and so lower the concentration available in the sterilizing chamber. A recent failure of a commercial ethylene oxide plant was attributed to the fact that the cardboard carton used to contai百 the articles being sterilized had become dry during the cold weather and therefore the humidity thery normally contained and which contributed to the production of sterilizing conditions was no longep available and sterilization was not achieved. It for this reason that ethylene oxide sterilization should always be controlled by bacteriological tests. Th 
adds to the complexity of the process and means that skilled staff must be available to supervise it.

Ethylene oxide has been used in a number of ways to disinfect and sterilize items of hospital use. One popular technique has been to adapt old steam autoclaves for use in gas sterilizing chambers (Spencer, and Bahnson, 1958; McCaughan, McMichael, Schuder, and Kirby, 1959; Freeman and Barwell, 1960). This can be done relatively simply, and so long as bacteriological control is used the method can be made to work.

The next obvious advance was to use specially designed machines in which all the variables could be independently controlled, and such machines are now available manufactured both in Germany and in the United States. The German machines, using high concentrations of gas at subatmospheric pressures, are more suitable for industrial use than for routine use in hospitals. The American machines, using a low concentration mixture and a rather higher temperature, can have provision made for humidifying the atmosphere and are provided with a fully automatic sterilizing cycle. Such machines are convenient but are also very expensive. A simpler technique was described by Bracken, Wilton-Davies, and Weale (1960) from Guy's Hospital; it consists of wrapping the object to be sterilized, in this case a heart-lung machine, in a plastic bag. This bag was evacuated first, using a converted hand vacuum cleaning device, gas was admitted to the bag, and after an appropriate dwell time the bag was again evacuated. This technique can in fact be made to work although bacteriological control suggests that it may be somewhat marginal, and it is possible that gas may escape through the bag. It is now understood that the bags themselves are being redesigned with a new plastic which is less permeable to ethylene oxide. This technique is undoubtedly cheaper than the use of a specially designed machine but it requires even closer supervision.

From this brief description of the uses of ethylene oxide, it will be clear that it is not an easy sterilizing technique to use. Because of its many variables ethylene oxide is probably the one sterilizing agent that can be effectively controlled only by bacteriological means. It is widely used in industrial practice where the loads are uniform and control staff is always available, but many feel that it is not entirely satisfactory for use in hospitals where such control may be more difficult to arrange. (For a short general review, see Kelsey, 1961.) There are also a number of reports both from America and from the United Kingdom of the routine use of ethylene oxide in sterilizing heart-lung machines and there is no doubt that when carefully used it can be satisfactory.
For the reasons already given it is necessary to examine methods other than ethylene oxide. Liquid chemical disinfectants are either of doubtful efficiency or are very inconvenient to use. Experience continues to show that physical methods of sterilization and disinfection are much more reliable than chemical ones. Of the physical methods available, steam is undoubtedly one of the most effective, and one about which there is most information. Two distinct possibilities exist here. First, Alder and Gillespie (1961) have described a technique using low temperature steam at subatmospheric pressures. This is done in a converted high-vacuum sterilizer. The vacuum ensures complete penetration by steam and also drying the load afterwards. These authors have shown that not only are vegetative organisms quickly killed but also that this process is effective against spores. This is an unexpected finding but evidence is being accumulated to show that it is a real one. At these temperatures many plastics and other heat-sensitive materials are quite undamaged, and it therefore seems important that this process should be considered for sterilizing heart-lung machines.

Another obvious line of approach is to use the newer heat-resistant plastics for constructing the heart-lung machines. This would enable them to be sterilized in modern high-vacuum sterilizers, which would allow not only rapid penetration by steam of the assembled equipment but would also enable it to be dried afterwards. Now that high-vacuum sterilizers are becoming commoner, it should not be difficult to arrange for experiments to test this possibility. The use of such heat-resistant plastics for heart-lung machines has been described by Esmond and his colleagues at the University of Maryland at Baltimore. Esmond has also described a still more radical approach to the problem. He considers that too much time is spent in cleaning, assembling, and sterilizing such equipment and that the logical answer is to make it disposable. He has now produced a system based on this assumption. This consists of an oxygenator, bubble-trap, and heat exchanger, which can be either purchased presterilized and regarded as disposable or cleaned and sterilized by steam after use (Esmond and Cowley, 1958; Esmond, Demetriades, and Cowley, 1959; Esmond, Stram, Kurad, Chyba, Attar, and Cowley, 1960).

The more closely the problem of sterilizing heartlung machines is examined the more apparent it becomes that the solution lies not in the development of more and more refined (and complex) sterilizing techniques for existing equipment, but in redesigning the heart-lung machine itself so that it can either be treated by reliable physical methods or be obtained 
as presterilized disposable units, as is already the case with the artificial kidney.

\section{REFERENCES}

Alder, V. G., and Gillespie, W. A. (1961). J. clin. Path., 14, 515. Bracken, A., Wilton-Davies, C. C., and Weale, F. E. (1960). Guy's Hosp. Rep., 109, 75.

Esmond, W. G., and Cowley, R. A. (1958). Amer. Surg., 24, 685.

-, Demetriades, A. D., and Cowley, R. A. (1959). Trans. Amer. Soc. art. intern. Org., 5, 163.
—, Stram, J. R., Kurad, W., Chyba, J., Attar, S., and Cowleyฮ R. A. (1960). Ibid., 6, 360.

Freeman, M. A. R., and Barwell, C. F. (1960). J. Hyg. (Lond.), 58, 337.

Kelsey, J. C. (1961). J. clin. Path., 14, 59.

Keown, K. K., Gilman, R. A., and Bailey, C. P. (1957). J. Amer. med Ass., 165, 781 .

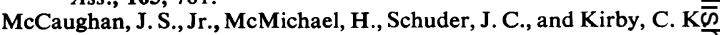
(1959). Surgery, 45, 648.

Spencer, F. C., and Bahnson, H. T. (1958). Bull. Johns Hopk. Hosp $102,241$. 